\title{
An Iterative Process for Nonlinear Monotonic Nonexpansive Operators in Hilbert Space
}

\author{
By W. G. Dotson, Jr.
}

Abstract. The following theorem is proved: Suppose $H$ is a complex Hilbert space, and $T: H \rightarrow H$ is a monotonic, nonexpansive operator on $H$, and $f \in H$. Define $S: H \rightarrow H$ by $S u=-T u+f$ for all $u \in H$. Suppose $0 \leqslant t_{n} \leqslant 1$ for all $n=1,2$, $3, \ldots$, and $\Sigma_{n=1}^{\infty} t_{n}\left(1-t_{n}\right)$ diverges. Then the iterative process $V_{n+1}=\left(1-t_{n}\right) V_{n}$ $+t_{n} S V_{n}$ converges to the unique solution $u=p$ of the equation $u+T u=f$.

It is well known that the equation $u+T u=f$ has a unique solution $u$ for each $f$ in a Hilbert space $H$ provided that $T: H \rightarrow H$ is monotonic and Lipschitzian (e.g., see [3]). The purpose of this paper is to show that if $T$ is nonexpansive (Lipschitz constant 1), then the Mann iterative process [1] will, under a certain condition, converge to this unique solution.

The normal Mann iterative process is defined by $V_{n+1}=\left(1-t_{n}\right) V_{n}+t_{n} T V_{n}$. We will use the condition that $\Sigma_{n=1}^{\infty} t_{n}\left(1-t_{n}\right)$ diverges, which has been extensively used by Groetsch [2] .

Theorem. Suppose $H$ is a complex Hilbert space, and $T: H \rightarrow H$ is a monotonic, nonexpansive operator on $H$, and $f \in H$. Define $S: H \rightarrow H$ by $S u=-T u+f$ for all $u \in H$. Suppose $0 \leqslant t_{n} \leqslant 1$ for all $n=1,2,3, \ldots$, and $\Sigma_{n=1}^{\infty} t_{n}\left(1-t_{n}\right)$ diverges. Then the iterative process $V_{n+1}=\left(1-t_{n}\right) V_{n}+t_{n} S V_{n}$ converges to the unique solution $u=p$ of the equation $u+T u=f$.

Proof. We first observe that $S$ is nonexpansive and satisfies $\operatorname{Re}(S x-S y, x-y)$ $\leqslant 0$ for all $x, y \in H$. Since $S p=p$, we get

$$
\begin{aligned}
\left\|V_{n+1}-p\right\|^{2}= & \left\|\left(1-t_{n}\right)\left(V_{n}-p\right)+t_{n}\left(S V_{n}-S p\right)\right\|^{2} \\
= & \left(1-t_{n}\right)^{2}\left\|V_{n}-p\right\|^{2}+2 t_{n}\left(1-t_{n}\right) \operatorname{Re}\left(S V_{n}-S p, V_{n}-p\right) \\
& +t_{n}^{2}\left\|S V_{n}-S p\right\|^{2} .
\end{aligned}
$$

Using $\operatorname{Re}\left(S V_{n}-S p, V_{n}-p\right) \leqslant 0, t_{n}\left(1-t_{n}\right) \geqslant 0$, and $\left\|S V_{n}-S p\right\| \leqslant\left\|V_{n}-p\right\|$, we get

$$
\left\|V_{n+1}-p\right\|^{2} \leqslant\left\{\left(1-t_{n}\right)^{2}+t_{n}^{2}\right\}\left\|V_{n}-p\right\|^{2}
$$

which can also be written

$$
\left\|V_{n+1}-p\right\|^{2} \leqslant\left\{1-2 t_{n}\left(1-t_{n}\right)\right\}\left\|V_{n}-p\right\|^{2} .
$$

Received April 15, 1975.

AMS (MOS) subject classifications (1970). Primary 47H15; Secondary 47H05, $65 \mathrm{~J} 05$.

Key words and phrases. Iteration, monotonic operators, nonexpansive operators. 
Upon iteration this yields

$$
\left\|V_{n+1}-p\right\|^{2} \leqslant\left\{\prod_{k=1}^{n}\left[1-2 t_{k}\left(1-t_{k}\right)\right]\right\}\left\|V_{1}-p\right\|^{2} .
$$

We note that $0 \leqslant 2 t(1-t) \leqslant 1 / 2$ for $0 \leqslant t \leqslant 1$. From the divergence of $\sum_{n=1}^{\infty} t_{n}\left(1-t_{n}\right)$ it now follows that $\lim _{n}\left\|V_{n+1}-p\right\|=0$, whence $\left\{V_{n}\right\}$ converges to $p$.

A particular case is of some interest, viz. $t_{n}=1 / n .(1 / n)(1-1 / n)=(n-1) / n^{2}$ $>1 / 2 n$ for $n>2$ establishes the divergence of $\sum_{n=1}^{\infty} t_{n}\left(1-t_{n}\right)$. There is however an alternate method in this particular case which gives the additional information of an error estimate. As before, we let $p$ denote the unique solution of $u+T u=f$, and we observe that

$$
\left\|S V_{n}-S p\right\| \leqslant\left\|V_{n}-p\right\| \leqslant\left\|V_{1}-p\right\|
$$

We have

$$
V_{n+1}=\frac{n}{n+1} V_{n}+\frac{1}{n+1} S V_{n}
$$

and so

$$
V_{n+1}-p=\frac{n}{n+1}\left(V_{n}-p\right)+\frac{1}{n+1}\left(S V_{n}-S p\right)
$$

whence

$$
\begin{aligned}
\left\|V_{n+1}-p\right\|^{2}= & \frac{n^{2}}{(n+1)^{2}}\left\|V_{n}-p\right\|^{2}+\frac{2 n}{(n+1)^{2}} \operatorname{Re}\left(S V_{n}-S p, V_{n}-p\right) \\
& +\frac{1}{(n+1)^{2}}\left\|S V_{n}-S p\right\|^{2} .
\end{aligned}
$$

Thus, we get

$$
(n+1)^{2}\left\|V_{n+1}-p\right\|^{2}-n^{2}\left\|V_{n}-p\right\|^{2} \leqslant\left\|V_{1}-p\right\|^{2} .
$$

The left-hand side collapses upon summation from $n=1$ to $n=N$ to yield

$$
(N+1)^{2}\left\|V_{N+1}-p\right\|^{2}-\left\|V_{1}-p\right\|^{2} \leqslant N \cdot\left\|V_{1}-p\right\|^{2} \text {. }
$$

Hence for each $N=1,2,3, \ldots$, we have

$$
\left\|V_{N+1}-p\right\|^{2} \leqslant(1 /(N+1))\left\|V_{1}-p\right\|^{2} .
$$

Thus $\left\{V_{n}\right\}$ converges to $p$ and for each $n$ we have

$$
\left\|V_{n+1}-p\right\| \leqslant \frac{1}{\sqrt{n+1}}\left\|V_{1}-p\right\| .
$$

Department of Mathematics North Carolina State University Raleigh, North Carolina 27607

1. W. G. DOTSON, JR., “On the Mann iterative process," Trans. Amer. Math. Soc., v. 149, 1970, pp. 65-73. 
2. C. W. GROETSCH, “A note on segmenting Mann iterates," J. Math. Anal. Appl., v. 40, 1972 , pp. 369-372.

3. E. H. ZARANTONELLO, Solving Functional Equations by Contractive Averaging, Technical Report No. 160, U. S. Army Math. Res. Center, Madison, Wisc., 1960.

4. E. H. ZARANTONELLO, "The closure of the numerical range contains the spectrum," Pacific J. Math., v. 22, 1967, pp. 575-595. MR 37 \#657. 